\title{
Nitric Oxide-Mediated Plasticity of Interconnections Between T-Stellate cells of the Ventral Cochlear Nucleus Generate Positive Feedback and Constitute a Central Gain Control in the Auditory System
}

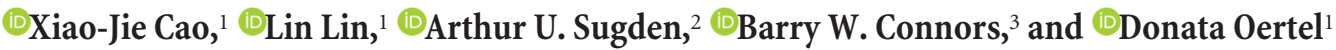 \\ ${ }^{1}$ Department of Neuroscience, School of Medicine and Public Health, Madison, Wisconsin 53705, ${ }^{2}$ Beth Israel Deaconess Medical Center, Center for Life \\ Sciences, Boston, Massachusetts 02115, and 3 Department of Neuroscience, Division of Biology and Medicine, Brown University, Providence, Rhode Island 02912
}

T-stellate cells in the ventral cochlear nucleus (VCN) form an ascending pathway that conveys spectral information from the cochlea to brainstem nuclei, the inferior colliculi, and the thalamus. The tonotopic array of T-stellate cells enhances the encoding of spectral peaks relative to their auditory nerve fiber inputs. The alignment of local collaterals and T-stellate cell dendrites within the isofrequency lamina suggests that the cells make connections within the isofrequency lamina in which they reside. Recordings from pairs of T-stellate cells in mice of both sexes revealed that firing in the presynaptic cell evoked responses in the postsynaptic cell when presynaptic firing was paired with depolarization of the postsynaptic cell. After such experimental coactivation, presynaptic firing evoked EPSCs of uniform amplitude whose frequency depended on the duration of depolarization and diminished over minutes. Nitric oxide (NO) donors evoked EPSCs in T-stellate cells but not in the other types of principal cells. Blockers of neuronal nitric oxide synthase (nNOS) and of NMDA receptors blocked potentiation, indicating that NO mediates potentiation. nNOS and its receptor, guanylate cyclase (NO-GC), are expressed in somata of T-stellate cells. Excitatory interconnections were bidirectional and polysynaptic, indicating that T-stellate cells connect in networks. Positive feedback provided by temporarily potentiated interconnections between T-stellate cells could enhance the gain of auditory nerve excitation in proportion to the excitation, generating a form of short-term central gain control that could account for the ability of T-stellate cells to enhance the encoding of spectral peaks.

Key words: choppers; hearing; nitric oxide; plasticity; tinnitus; ventral cochlear nucleus

Significance Statement

T-stellate cells are interconnected through synapses that have a previously undescribed form of temporary, nitric oxide-mediated plasticity. Coactivation of neighboring cells enhances the activation of an excitatory network that feeds back on itself by enhancing the probability of EPSCs. Although there remain gaps in our understanding of how the interconnections revealed in slices contribute to hearing, our findings have interesting implications. Positive feedback through a network of interconnections could account for how T-stellate cells are able to encode spectral peaks over a wider range of intensities than many of their auditory nerve inputs (Blackburn and Sachs, 1990; May et al., 1998). The magnitude of the gain may itself be plastic because neuronal nitric oxide synthase increases when animals have tinnitus (Coomber et al., 2015).

\section{Introduction}

Mammalian hearing depends on the brain's ability to use the representation of the physical attributes of sound from the co-

Received Jan. 21, 2019; revised May 24, 2019; accepted May 30, 2019.

Author contributions:X.-J.C., L.L., A.U.S., and D.O. designed research;X.-J.C. and L.L. performed research;X.-J.C., L.L., B.W.C., and D.O. analyzed data; X.-J.C., L.L., and D.O. wrote the first draft of the paper; L.L., A.U.S., B.W.C., and D.0. edited the paper; $D .0$. wrote the paper.

This work was supported by the National Institutes of Health (Grants DC00176 and DC016861), by a Fall Research Fellowship from the Wisconsin Alumni Research Foundation, by the University of Wisconsin Foundation, and by the Mary Herman and Lucien Rubinstein Distinguished Professorship (D.0.). Our work depends on the superb adminis- chlea to compute biologically important features: where sounds arise and what they mean. The beginnings of those computations take place in the ventral cochlear nucleus (VCN). In all mammals, T-stellate cells feed acoustic input to a wide range of targets

trative help from Rebecca Welch and her team. We are also grateful for the exceptionally thoughtful comments of two reviewers.

The authors declare no competing financial interests.

Correspondence should be addressed to Donata 0ertel at doertel@wisc.edu.

https://doi.org/10.1523/JNEUROSCI.0177-19.2019

Copyright $\odot 2019$ the authors 
(Oertel et al., 1990, 2011; Schofield et al., 2014). Individual T-stellate cells monitor the rise and fall of energy within the narrow frequency range to which they are tuned. Sounds evoke tonic firing (chopping), the rate of which is a monotonic function of intensity (Rhode et al., 1983; Smith and Rhode, 1989). T-stellate cells effectively encode sound envelopes and amplitude modulation rates between 20 and $150 \mathrm{~Hz}$ that are especially important for understanding speech (Frisina et al., 1990; Wang and Sachs, 1992, 1994; Laudanski et al., 2010). As a population, T-stellate cells provide an ongoing representation of the spectrum of sounds that impinge on one ear that is better than the representation of spectral peaks in their auditory nerve inputs (Blackburn and Sachs, 1990; May et al., 1998). Sideband inhibition to T-stellate cells enhances the contrast between spectral peaks and valleys relative to their auditory nerve inputs (Rhode and Greenberg, 1994). It is striking that T-stellate cells carry information about sounds that cochlear implant users use and they fail to carry information about the fine structure of sounds that cochlear implant users cannot use (Shannon et al., 1995).

The present study reveals interconnections between neighboring T-stellate cells within the VCN (see Fig. 1A). T-stellate cells in the multipolar cell area of the posteroventral cochlear nucleus (pVCN) have dendrites aligned with an isofrequency band parallel to the five or six auditory nerve fibers from which they receive acoustic input (Oertel et al., 1990; Doucet and Ryugo, 1997; Ferragamo et al., 1998). They also have local axonal collaterals and terminals that are confined to the same isofrequency band (Oertel et al., 1990, 2011). Because the multipolar cell area comprises mostly T-stellate cells, we set out to test the hypothesis that $\mathrm{T}$-stellate cells contact other T-stellate cells within their isofrequency band with dual-cell recordings in slices.

We find that coactivation of T-stellate cells potentiates a polysynaptic network via a mechanism that requires nitric oxide (NO) signaling. NO is a small, reactive, short-lived signaling molecule with a lipid solubility that makes diffusion of NO rapid even across anatomical barriers (Garthwaite et al., 1988; Furchgott and Jothianandan, 1991; Batchelor et al., 2010). In neurons, the elevation of intracellular $\mathrm{Ca}^{2+}$, especially by entry through NMDA receptors, activates neuronal nitric oxide synthase (nNOS) through calmodulin (Sattler et al., 1999). nNOS catalyzes the conversion of L-arginine to citrulline and NO (Bredt and Snyder, 1992; Boehning and Snyder, 2003). NO commonly binds NOsensitive guanylate cyclase in surrounding tissue (NO-GC) to increase cGMP (van Staveren et al., 2005; Zhou and Zhu, 2009). In presynaptic terminals, signaling through NO-GC influences a variety of functions (Garthwaite et al., 1988; Ahern et al., 2002; Kopp-Scheinpflug et al., 2015). With lower affinity, NO can also modify presynaptic or postsynaptic molecular components by S-nitrosylation or 3 nitrotyrosination (Bradley and Steinert, 2016).

Positive feedback in a network of interconnected T-stellate cells has important, as yet untested, implications. It can increase the gain in an important ascending auditory pathway and could account for why T-stellate cells encode spectral properties more effectively than their auditory nerve inputs. Furthermore, nNOS increases when animals have tinnitus (Coomber et al., 2014, 2015), raising the possibility that the magnitude of the gain is itself plastic.

\section{Materials and Methods}

Protocols. The protocols used in the present study were approved by the Institutional Animal Care and Use Committee of the School of Medicine and Public Health at the University of Wisconsin-Madison (M005303).
They are in accordance with the recommendations in the Guide for the Care and Use of Laboratory Animals of the National Institutes of Health.

Mice. Mice for the present study came from a colony of CBA/CaJ mice bred in-house (stock \#000654; The Jackson Laboratory) that have good hearing even as they age (Kujawa and Liberman, 2009), although they do suffer from hidden hearing loss (Sergeyenko et al., 2013). When not enough of these mice were available, we purchased outbred, ICR mice from Envigo (formerly Harlan Laboratories). Recordings from 138 cells from 138 mice form the basis of this study; 71 were CBA and 67 were ICR. ICR mice had normal hearing at the ages at which the present experiments were done but they lose hearing as they age (Drayton and NobenTrauth, 2006). We pooled the results from male and female mice of both strains because we have not observed differences, and we also have no reason to expect to find differences on the basis of tests of hearing, between males and females or between strains.

Solutions. The normal extracellular solution in which slices were cut and maintained during recordings contained the following (in $\mathrm{mM}$ ): 130 $\mathrm{NaCl}, 3 \mathrm{KCl}, 1.2 \mathrm{KH}_{2} \mathrm{PO}_{4}, 2.4 \mathrm{CaCl}_{2}, 1.3 \mathrm{MgSO}_{4}, 20 \mathrm{NaHCO}_{3}, 6$ HEPES, 10 glucose, and 0.4 ascorbic acid saturated with $95 \% \mathrm{O}_{2} / 5 \% \mathrm{CO}_{2}, \mathrm{pH}$ 7.3-7.4, between $24^{\circ} \mathrm{C}$ and $33^{\circ} \mathrm{C}$. The osmolality was $306 \mathrm{mOsm} / \mathrm{kg}$ (3D3 Osmometer; Advanced Instruments). Recording pipettes were filled with a solution containing the following (in $\mathrm{mM}$ ): 108 potassium gluconate, 9 HEPES, 9 EGTA, $4.5 \mathrm{MgCl}_{2}$, 14 phosphocreatine (tris salt), 4 ATP (Na salt), and 0.3 GTP (tris salt). The $\mathrm{pH}$ was adjusted to 7.4 with $\mathrm{KOH}$; the osmolality was $303 \mathrm{mOsm} / \mathrm{kg}$. PBS contained the following (in $\mathrm{mm}$ ): 10 phosphate buffer, $2.7 \mathrm{KCl}, 137 \mathrm{NaCl}, \mathrm{pH} 7.4$, at $25^{\circ} \mathrm{C}$. All chemicals were from Sigma-Aldrich unless stated otherwise.

Brain slices. Coronal slices of the VCN were made from mice aged between postnatal day 16 (P16) and P22. Slices $\sim 250 \mu \mathrm{m}$ thick were cut with a vibrating microtome (Leica, VT 1000S) and placed in a recording chamber $(\sim 0.6 \mathrm{ml})$ superfused with normal saline at 5 to $6 \mathrm{ml} / \mathrm{min}$. The recording chamber and micromanipulators (Sutter Instruments) were mounted on a movable stage (Siskiyou) under a compound microscope (Zeiss Axioskop) and viewed through a $63 \times$ water-immersion objective with the image displayed through a Hamamatsu CCD camera (C2400$77 \mathrm{AH})$ on a video monitor. The temperature was measured between the inflow of the chamber and the tissue with a Thermalert thermometer (Physitemp) through a small thermistor (IT-23, Physitemp, diameter: $0.1 \mathrm{~mm}$ ). The output of the Thermalert thermometer was fed into a custom-made, feedback-controlled heater that heated the saline in glass tubing ( $1.5 \mathrm{~mm}$ inner, $3 \mathrm{~mm}$ outer diameter) just before it reached the chamber to keep the temperature between $31^{\circ} \mathrm{C}$ and $33^{\circ} \mathrm{C}$. An adjustable delay in the controller for the heater prevented temperature oscillations. Recordings were generally made within $2 \mathrm{~h}$ after slices were cut.

Electrophysiology. Patch-clamp recordings were made with pipettes of borosilicate glass that had resistances between 4 and $8 \mathrm{M} \Omega$. Recordings were made with a Multiclamp 700B amplifier (Molecular Devices). Records were digitized at $50 \mathrm{kHz}$ and low-pass filtered at $10 \mathrm{kHz}$. Series resistances were between 10 and $14 \mathrm{M} \Omega$; recordings in which series resistances were $>14 \mathrm{M} \Omega$ were disregarded. All reported results were from recordings in which between $60 \%$ and $90 \%$ of the series resistance could be compensated online with $10 \mu$ s lag; no corrections were made for errors in voltage that resulted from uncompensated series resistance. The output was digitized through a Digidata 1320A interface (Molecular Devices) and fed into a computer. Stimulation and recording was controlled by pClamp 9.2 software (Molecular Devices). Analyses were performed with MiniAnalysis (Synaptosoft) and Clampfit version 10.7. All reported voltages were compensated for a $-12 \mathrm{mV}$ junction potential. Statistical analyses were made with Origin software (2016); the results are given as means $\pm \mathrm{SD}$, with $n$ being the number of cells in which the measurement was made.

Double-immunofluorescence staining. Mice of both sexes between 3 and 6 weeks of age were used for these experiments. The mice were anesthetized with an intraperitoneal injection of anesthetic $(100 \mathrm{mg} / \mathrm{kg}$ ketamine; $10 \mathrm{mg} / \mathrm{kg}$ xylazine) and perfused through the heart with PBS followed by cold $4 \%$ paraformaldehyde. The brains were postfixed in the same fixative overnight at $4^{\circ} \mathrm{C}$. The cochlear nuclei were then sectioned into $40 \mu \mathrm{m}$ parasagittal sections with a vibratome (Leica, 1000S). 
To localize nNOS and NO-GC, free-floating sections were permeabilized using $0.15 \%$ Triton X-100 (20 min), blocked with 3\% bovine serum albumin and the Fab fragment of anti-mouse IgG (715-007-003, Jackson ImmunoResearch) for $1 \mathrm{~h}$ and then incubated in a mixture of primary antibodies at room temperature overnight. Two antibodies specific for nNOS (sheep, 1:500, AB1529, Millipore; and rabbit, 1:1000, ab76067, Abcam) and one specific for the NO-GC $\beta 1$ subunit (mouse, 1:200, sc514183, Santa Cruz Biotechnology) were used. Both nNOS antibodies are directed against the C-terminal of the nNOS protein. After several washes with PBS, sections were incubated with secondary antibodies at room temperature (2 h). Cy2 anti-sheep (1:500; 713-225-147, Jackson ImmunoResearch) and Alexa Fluor 488 anti-rabbit (1:500; A21206, Invitrogen) secondary antibodies were used to detect nNOS and Alexa Fluor 568 anti-mouse secondary antibody (1:500; A10037, Invitrogen) was used to detect NO-GC. Images were taken using a Nikon A1 confocal microscope and processed in ImageJ.

Primary antibodies were tested by the laboratories of origin. Preabsorbed secondary antibodies were chosen to avoid cross-reactivity with other antibodies. Staining without primary antibodies was performed to exclude autofluorescence or specific background labeling by secondary antibodies. No nonspecific staining was observed.

Experimental design and statistical analysis. Most experiments were designed to compare control and experimental conditions in the same cell or pair of cells. The number of times an experiment was repeated is reported for each experiment. In Figure 4, the amplitudes of EPSCs in the presence and absence of an NO donor are compared statistically. All statistical analyses were made with Origin Pro 2016 Software. Most comparisons were made using a paired-sample Student's $t$ test. When data were not normally distributed, comparisons were made with the MannWhitney $U$ test. Details about box-and-whisker plots are described in the legend to Figure 6.

Numbering of panels in illustrations. Capital letters designate separate measurements. Where multiple traces from a single cell or a single pair are shown, the panels are designated in lowercase letters.

\section{Results}

\section{Interconnections and their potentiation}

Knowing that local collaterals of T-stellate cells lie in the same isofrequency lamina as the cell bodies and dendrites (Oertel et al., 1990), we recorded pairs of cell bodies, between 180 and $230 \mu \mathrm{m}$ apart, that lay aligned between fascicles of auditory nerve fibers in the whole-cell configuration (Fig. 1A). T-stellate cells were identified by their electrophysiological characteristics in the current-clamp mode. In T-stellate cells suprathreshold depolarizations evoked action potentials that occurred at regular intervals for the duration of the depolarization; action potentials were brief and were followed by a simple undershoot that rose monotonically (Oertel et al., 1990; Fujino and Oertel, 2001; Cao and Oertel, 2011); hyperpolarizations sagged back toward rest relatively slowly (Rodrigues and Oertel, 2006). After being identified in current-clamp mode, the target cell was switched to voltageclamp mode to measure EPSCs.

Only five of the first 23 recordings from pairs of T-stellate cells appeared to be connected and those connections were weak. Action potentials were evoked by depolarizing one cell in currentclamp mode while EPSCs were monitored in voltage-clamp mode in the other. If there was no response, then synaptic connections were tested in the opposite direction; action potentials were evoked in current-clamp mode in the second cell and the first was put in voltage-clamp mode to monitor responses. One example of such a recording is shown in Figure $1 B$. Driving the presynaptic cell at 15 action potentials/s elicited no synaptic responses (Fig. $1 \mathrm{Ba}$ ); increasing the firing rate to $74 / \mathrm{s}$ evoked a weak response; 89 presynaptic action potentials evoked 12 EPSCs (Fig. $1 B b)$. EPSCs were of approximately similar magnitude as long as they were present. The failure of synaptic responses to follow presynaptic firing consistently within 1 or $2 \mathrm{~ms}$ led us to conclude that these two T-stellate cells were connected through one or more excitatory interneurons and that the connection was polysynaptic. It was impossible to measure a synaptic delay because rapid presynaptic firing was required to evoke even a few EPSCs so that it was unclear which spike elicited any one EPSC. In all the connected pairs in which connections were observed at rest, rapid firing evoked only few EPSCs.

The unexpectedly infrequent observation of weak connections raised the question of whether T-stellate cells might be connected by synapses that are potentiable. As there are other examples of synapses that can be functionally observed only after potentiation, we tested a common potentiation protocol by pairing presynaptic firing with postsynaptic depolarization (Wigström et al., 1986; Isaac et al., 1995; Liao et al., 1995).

Pairing of presynaptic firing and postsynaptic depolarization did indeed potentiate connections between T-stellate cells. One example is shown in Figure 1C. With both cells held at $-65 \mathrm{mV}$, no synaptic responses were evident (Fig. $1 \mathrm{Ca}$ ). One of the two cells was then depolarized to $+30 \mathrm{mV}$ for $36 \mathrm{~s}$. After the voltage was returned to $-65 \mathrm{mV}$, there still were no EPSCs (Fig. 1Cb). Next, one of the cells was placed under current-clamp conditions and depolarized with current to fire action potentials, but there were still no EPSCs in the second cell other than an occasional spontaneous mEPSC (Fig. 1Cc). Only after postsynaptic depolarization was paired with presynaptic firing were EPSCs observed at $-65 \mathrm{mV}$ (Fig. 1Cd). EPSCs were of approximately uniform magnitude and kinetics, having $10-90 \%$ rise times of $0.2 \mathrm{~ms}$ and decay time constants $\left(\tau_{\mathrm{D}}\right)$ of $\sim 1 \mathrm{~ms}$ (Fig. 1Ce). The uniform magnitude of EPSCs implies that potentiation governs the probability and not the amplitude of EPSCs. The probability of EPSCs faded over $\sim 1 \mathrm{~min}$. To date, we have not observed EPSCs that were temporally locked to single presynaptic action potentials. Figure $1 D$ shows the absence of temporal locking. After potentiation in this pair of T-stellate cells, action potentials occurred regularly but slightly faster than the regularly occurring EPSCs (Fig. 1Da). The timing of EPSCs relative to the firing of action potentials varies widely (Fig. $1 D b$ ).

The results of the present study are based on recordings from 57 pairs of T-stellate cells. In the first 23 pairs, presynaptic firing (without postsynaptic depolarization) evoked EPSCs in five of those pairs. In 34 more pairs, presynaptic firing was paired with postsynaptic depolarization to evoke EPSCs. In summary, in 5/57 pairs, presynaptic firing alone was sufficient to evoke EPSCs in the postsynaptic cell; in 29/34 pairs, pairing of presynaptic firing with postsynaptic depolarization evoked EPSCs.

The extent of potentiation depends on the duration of postsynaptic depolarization and fades over one to several minutes (Fig. 2). In a dual recording, the presynaptic cell was depolarized with current to fire continually at 35 action potentials/s while the postsynaptic cell was clamped at $-65 \mathrm{mV}$; the two cells initially showed no sign of being connected (Fig. 2a). After having been at $+30 \mathrm{mV}$ for $36 \mathrm{~s}$ while the presynaptic cell continued to fire and the postsynaptic voltage was returned to $-65 \mathrm{mV}$, postsynaptic EPSCs appeared (Fig. 2b). After EPSCs faded and a further pairing of presynaptic firing with postsynaptic depolarization to +30 $\mathrm{mV}$ for $72 \mathrm{~s}$, the frequency and persistence of EPSCs increased even further (Fig. 2c). The mean amplitude of EPSCs remained approximately uniform throughout the experiment. Figure $2 d$ summarizes the course of the experiment. Pairing of depolarization with presynaptic firing increased the probability of observing EPSCs over $\sim 2$ min but then EPSCs stopped. Longer pairing resulted in more frequent EPSCs for a longer time, $\sim 5 \mathrm{~min}$. The 


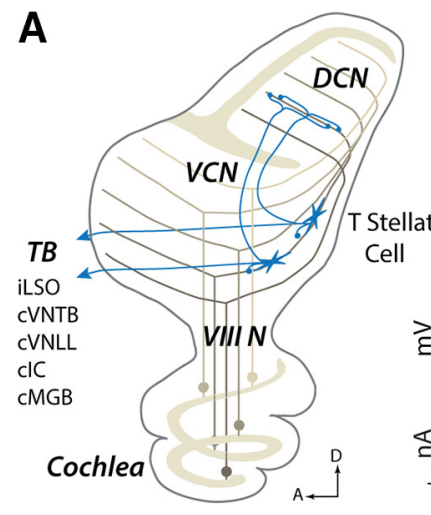

C

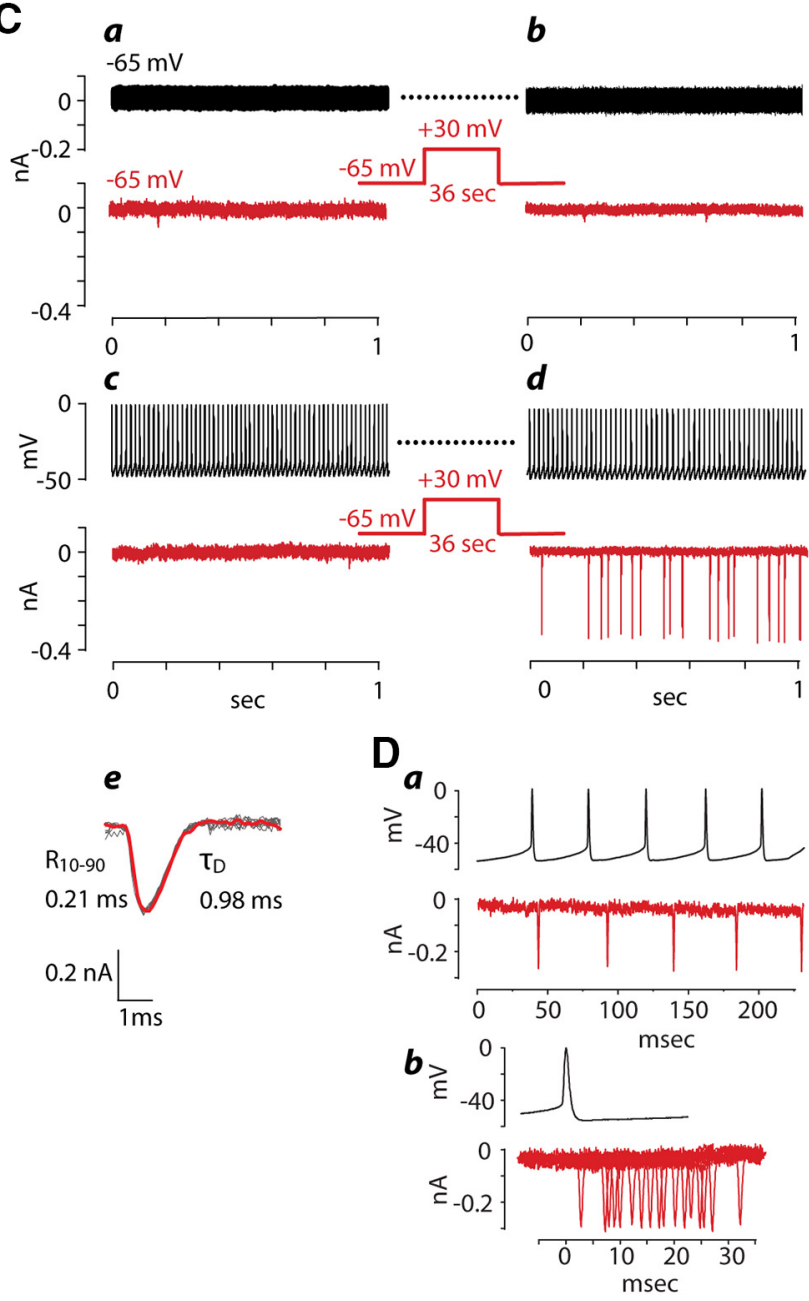

Figure 1. A, Schematic diagram illustrating what is known about connections of T-stellate cells in the cochlear nuclei is represented in a parasagittal view. Auditory nerve fibers (VIIIN), the axons of spiral ganglion cells, carry information from the cochlea to the VCN and dorsal cochlear nucleus (DCN). The topographic pattern of innervation by these fibers imposes a tonotopic organization on the VCN and DCN; fibers tuned to low frequencies (dark brown) terminate ventrally and those tuned to high frequencies (light brown) terminate dorsally. The granule cell lamina ( $\tan )$ separates the unlayered VCN from the layered DCN. The dendrites of T-stellate cells (blue stars) lie aligned with auditory nerve fibers along an isofrequency lamina. Local collateral branches of their axons terminate within the same isofrequency lamina as their dendrites in the VCN. A collateral branch innervates the same isofrequency lamina in the deep layer of the DCN. The main axon exits the VCN through the trapezoid body (TB) to innervate the ipsilateral lateral superior olive (iLSO), contralateral ventral nucleus of the trapezoid body (CVNTB), mainly contralateral inferior colliculus $(\mathrm{ClC})$, and the contralateral medial geniculate body of the thalamus (CMGB). B, One of the few examples of functional interconnections between two T-stellate cells under resting conditions. $\boldsymbol{B a}$, A dual recording illustrates that 15 action potentials/s evoked by a small depolarizing current $(25 \mathrm{pA})$ in the presynaptic cell elicited no postsynaptic currents in
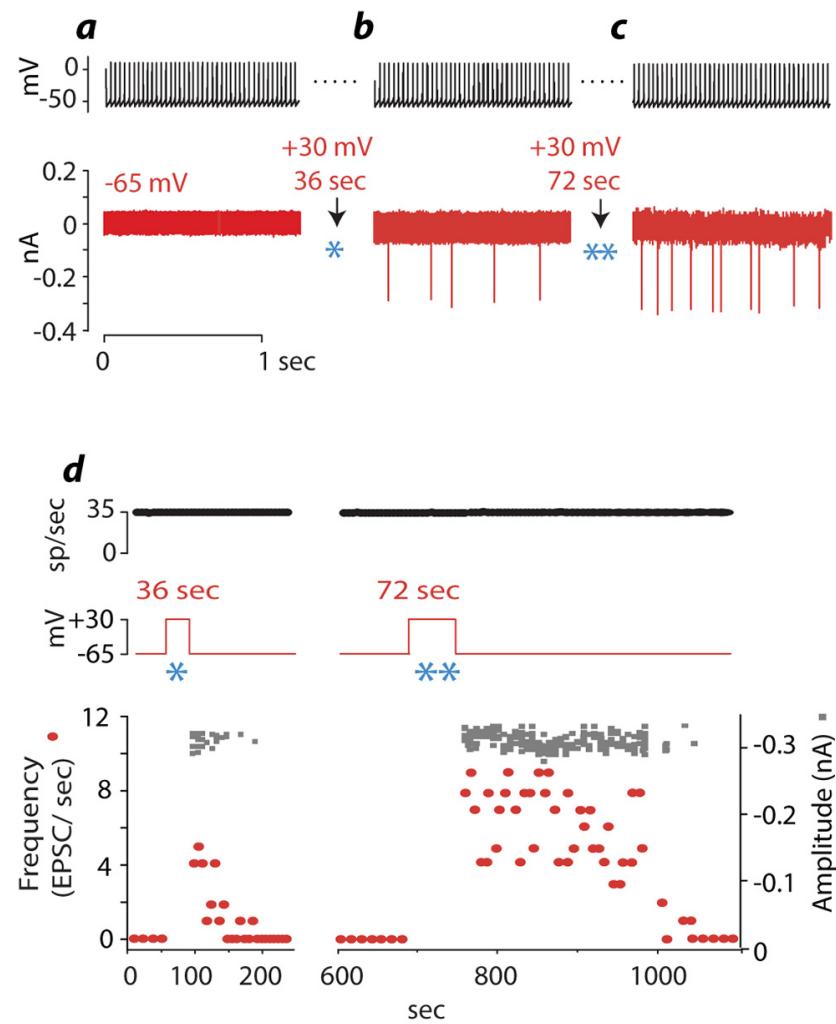

Figure 2. Dynamics of potentiation of interconnections between T-stellate cells illustrated in a dual recording. $\boldsymbol{a}$, When the presynaptic cell was caused to fire, no EPSCs were observed postsynaptically. $\boldsymbol{b}$, After pairing of presynaptic firing with postsynaptic depolarization for $36 \mathrm{~s}$ $\left({ }^{*}\right)$, EPSCs of approximately uniform amplitude appeared. $c$, After the EPSCs faded, the postsynaptic cell was depolarized again for a longer period, $72 \mathrm{~s}\left({ }^{* *}\right)$. After the postsynaptic voltage was returned to rest, EPSCs occurred more frequently than before. $\boldsymbol{d}$, Time course of this experiment summarized in the plot of the frequency and amplitude of EPSCs as a function of time. Pairing presynaptic firing and postsynaptic depolarization evoked EPSCs whose frequency (red symbols) waned over $\sim 2 \mathrm{~min}$. A longer pairing (72 s) evoked more EPSCs that remained potentiated for $2 \mathrm{~min}$ and then faded over the next $2 \mathrm{~min}$. The amplitude of EPSCS remained constant throughout the experiment.

fading of EPSCs was irregular; we could not fit it with an exponential time course. The amplitude of EPSCs was independent of potentiation, staying constant over the course of the entire experiment that lasted $\sim 18 \mathrm{~min}$ (Fig. $2 d$, gray rectangles).

the second. $\boldsymbol{B} \boldsymbol{b}$, A stronger depolarization (100 pA) that evoked 74 action potentials/s elicited EPSCs of approximately uniform size in the second. The latencies between action potentials and EPSCS were variable suggesting that EPSCS are polysynaptic. C, Pairing of presynaptic (black) firing with postsynaptic (red) depolarization potentiated an interconnection between a pair of T-stellate cells recorded simultaneously. $\boldsymbol{C} \boldsymbol{a}$, No EPSCs were seen in either cell when the voltage of both cells was held near the resting potential. $\boldsymbol{C} \boldsymbol{b}$, After depolarizing the postsynaptic cell to $+30 \mathrm{mV}$ for $36 \mathrm{~s}$ while the presynaptic cell continued to be clamped at $-65 \mathrm{mV}$ again, no responses were observed. Cc, Next, the presynaptic cell was recorded in current-clamp conditions and depolarized to fire 59 action potentials/s. Again no responses were recorded. Cd, Only when presynaptic firing was paired with depolarization were EPSCs evoked. All EPSCs in the postsynaptic cell were of approximately uniform amplitude. Dashed lines indicate that the presynaptic cell continued firing during the depolarization as before and after. Ce, 10 EPSCs are superimposed in gray and the average is superimposed in red. The $10-90 \%$ rise time $\left(R_{10-90}\right)$ and decay time constant $\left(\tau_{D}\right)$ of the average are shown. $\mathbf{D a}$, Traces from a dual recording show that action potentials in the presynaptic cell are not locked to the timing of EPSCs in the postsynaptic cell. $\boldsymbol{D} \boldsymbol{b}$, Recordings of EPSCs aligned with respect to the action potential show that their occurrence is not locked in time. In this and in all following figures, multiple traces recorded from one cell or one pair are designated with lowercase letters. Recordings from separate cells or pairs are designated with capital letters. 
A

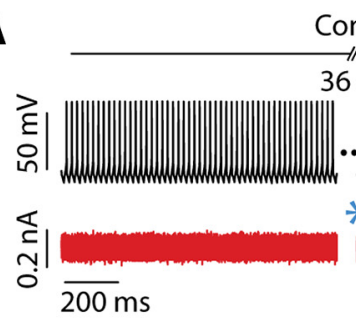

Control

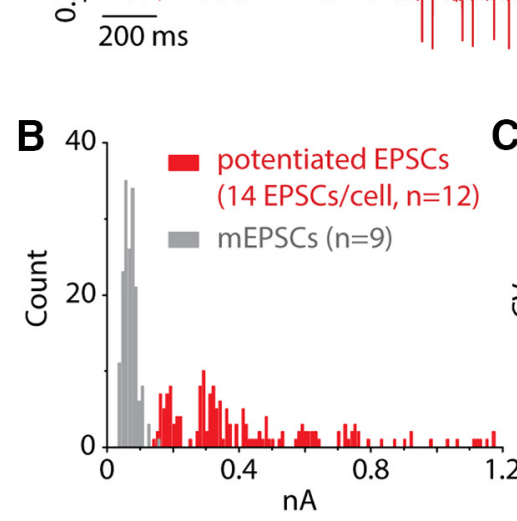

D

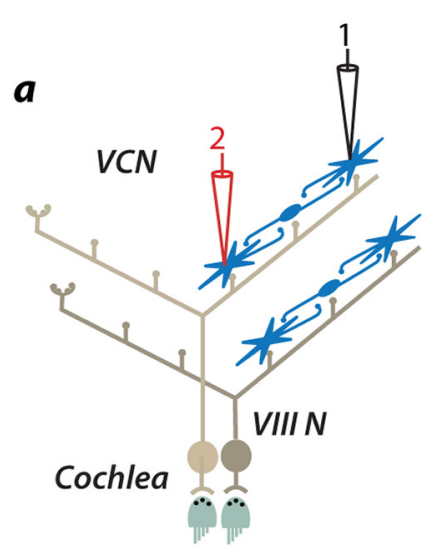

$40 \mu \mathrm{M}$ DNQX

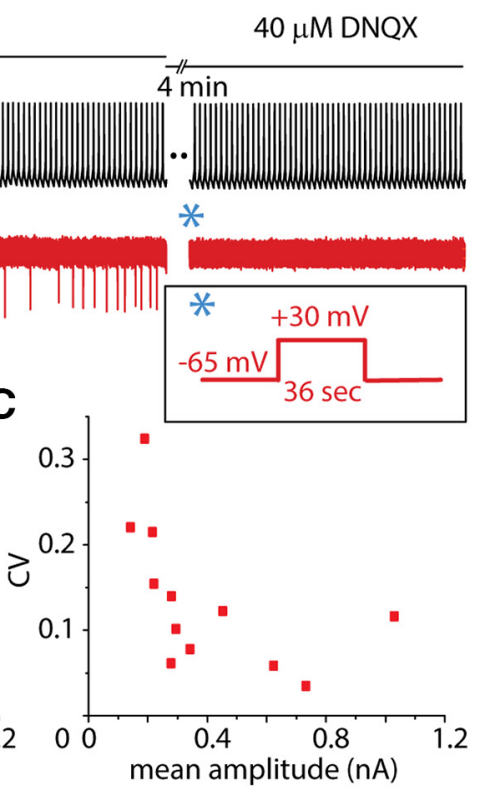

1

b

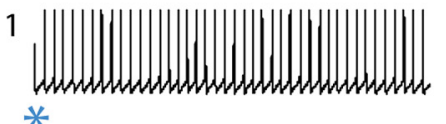

2

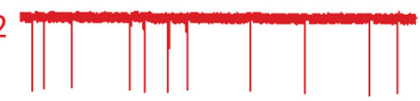

$200 \mathrm{~ms}$

$60 \mathrm{mV}$
$0.4 \mathrm{nA}$

*

C

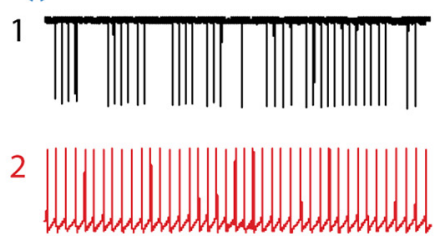

Figure 3. Interconnections are glutamatergic, variable in size, and bidirectional. $\boldsymbol{A}$, After EPSCS were evoked in the postsynaptic cell and faded away, the application of $40 \mu \mathrm{m}$ DNQX after a subsequent pairing blocked the EPSCs. $\boldsymbol{B}$, Potentiated EPSCs evoked by stimulation of other T-stellate cells (red) are larger than mEPSCs (gray) measured from some of the same cells before potentiation. The amplitude distribution of EPSCS evoked in the postsynaptic cells of paired recordings after potentiation has peaks. To give a representative picture, only the first 14 evoked EPSCs were measured from each of 12 postsynaptic cells. C, The CV (SD/mean) of the amplitude of all evoked EPSCs in those same 12 postsynaptic cells varies. Da, Schematic diagram depicts a dual recording. $\boldsymbol{D} \boldsymbol{b}$, After pairing presynaptic firing with the postsynaptic voltage protocol shown in the inset $\left(^{*}\right)$, action potentials in cell 1 (black) evoked EPSCs in cell 2 (red). DC, The roles of the two recorded cells were then reversed. After pairing action potentials in cell 2 with depolarization of cell $1{ }^{*}$ ), firing in cell 2 evoked EPSCs in cell 1. In both cells EPSCs were approximately uniform in size. Inset, ${ }^{*}$, Voltage protocol in postsynaptic cell that, when paired with presynaptic firing, resulted in potentiation.

Potentiated EPSCs were blocked by $40 \mu \mathrm{M}$ 6,7-dinitroquinoxaline-2,3(1H,4H)-dione (DNQX), an AMPA receptor antagonist. One experiment is illustrated in Figure 3A. As usual, presynaptic action potentials evoked no EPSCs at rest. After pairing presynaptic firing with postsynaptic depolarization, EPSCs of uniform amplitude appeared. After $1.5 \mathrm{~min}$, those EPSCs faded. Addition of DNQX to the bath prevented the appearance of EPSCs after a second potentiation in $2 / 2$ cells. It is not surprising that no NMDA component was evident in EPSCs because NMDA receptors in T-stellate cells are blocked by $\mathrm{Mg}^{2+}$ at -65 $\mathrm{mV}$ (Cao and Oertel, 2010). We cannot know whether DNQX blocked all or only some excitatory connections in the polysynaptic pathway, but our results are consistent with recorded EPSCs being glutamatergic.

EPSCs evoked by firing of the presynaptic T-stellate cell with or without postsynaptic depolarization were of relatively uniform amplitude in any one pair (34/ 34) (Fig. 2d), but their amplitudes differed between cells. The amplitude distribution of potentiated EPSCs recorded from 12 pairs at $-65 \mathrm{mV}$ is shown in Figure $3 B$ (red). To represent cells equally, the amplitude of only the first 14 evoked EPSCs from each cell are plotted. They were distinctly larger than spontaneous mEPSCs recorded before potentiation (Fig. $3 B$, gray), ranging between 130 and $1200 \mathrm{pA}$. The amplitudes of EPSCs were surprisingly uniform in each cell, showing neither facilitation nor depression. Figure $3 C$ is a plot of the coefficients of variation (CV; SD/mean) of EPSC amplitude calculated for each of the cells illustrated in Figure $3 B$. The CVs were indeed generally small, with the greatest variation observed in the smallest EPSCs, probably reflecting noise in the recordings. The mean $\mathrm{CV}$ was $0.122 \pm 0.067(n=12)$. For comparison, the CVs of amplitudes of minimal responses to shocks of the auditory nerve in T-stellate cells (Cao and Oertel, 2010) ranged between 0.07 and 0.31 , with a mean of $0.17 \pm 0.09, n=7$. The average amplitude of mEPSCs in the recordings shown in Figure $3 B$ was $70 \mathrm{pA}$; a separate estimate in the presence of tetrodotoxin (TTX) is $60.9 \pm 23.0 \mathrm{pA}$ (Fig. $4 C c$ ). These estimates were smaller than mEPSCs measured with $\mathrm{Cs}^{+}$containing pipettes in T-stellate cells in the presence of TTX, the mean amplitude of which was $88 \mathrm{pA}$ (Gardner et al., 1999) and 85 pA (Cao et al., 2008). The difference in estimates probably arose from relatively poorer space clamping with pipettes that lack $\mathrm{Cs}^{+}$. We conclude that most potentiated EPSCs are likely to be multivesicular.

\section{Interconnections are bidirectional}

Unidirectional connections were measured in more than half of pairs tested (20/ 29). We therefore tested directly whether connections are bidirectional (Fig. 3D). First, cell 1 was held in current-clamp mode and depolarized with current to fire steadily while cell 2 was held in voltage-clamp mode at $-65 \mathrm{mV}$. After pairing of presynaptic firing with postsynaptic depolarization to $+30 \mathrm{mV}$ for $36 \mathrm{~s}$ (Fig. 3A, inset), firing in cell 1 evoked EPSCs of uniform magnitude in cell 2 (Fig. 3Db). Then, cell 1 was clamped at $-65 \mathrm{mV}$ while cell 2 was caused to fire. After pairing depolarization of cell 1 with firing in cell 2, EPSCs of uniform magnitude were recorded in cell 1 (Fig. 3Dc). Potentiating connections in one direction did not cause potentiation of the connection in the opposite direction. Connections were bidirectional in $4 / 4$ connected pairs tested, but the strength of connections differed in the two directions. 
A
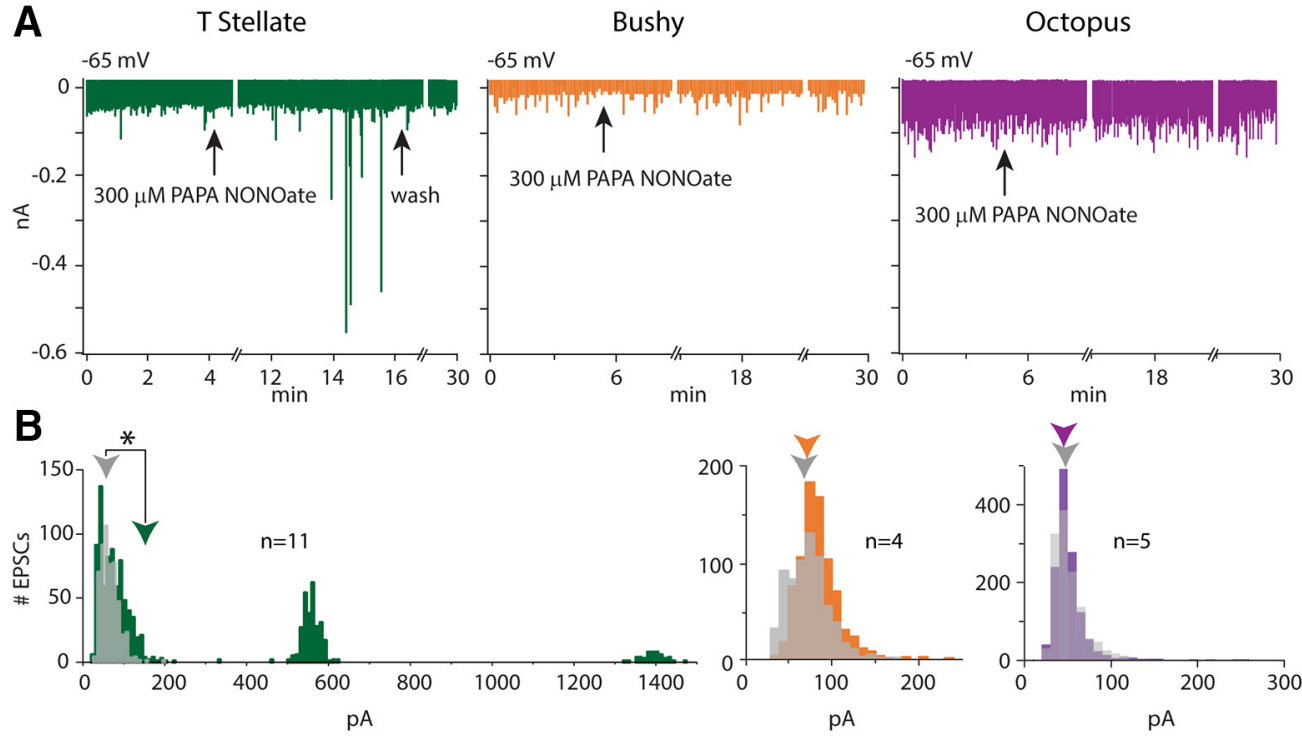

\section{C}

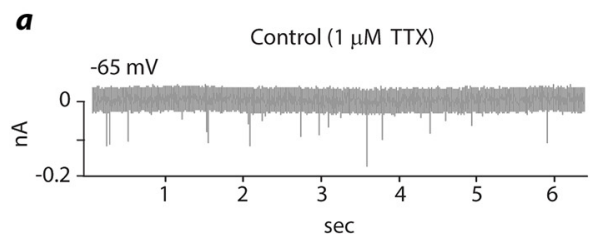

T Stellate

$\boldsymbol{b}$

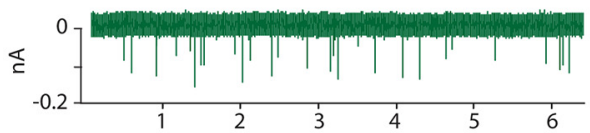

$c$

D
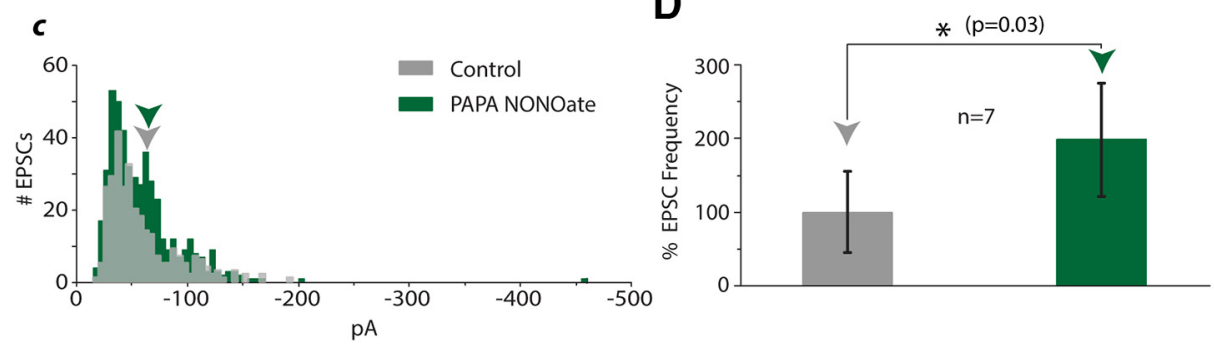

Figure 4. Comparison of action of the NO donor, PAPA NONOate, on T-stellate cells with its action on the other groups of principal cells of the VCN, bushy and octopus cells. Asterisk denotes a significant difference with $p<0.05$. A, Recordings of EPSCs in a T-stellate cell (green), a bushy cell (orange), and an octopus cell (purple) show that PAPA NONOate evoked large EPSCS, not of uniform amplitude, in the T-stellate cell, but not in the bushy or octopus cell. $\boldsymbol{B}$, Histograms of amplitudes of EPSCs recorded from $n$ cells in each group show that PAPA NONOate caused no change in the mean amplitude of EPSCs in bushy cells $(p=0.5)$ or octopus cells $(p=0.9)$. In the presence of PAPA NONOate, spontaneous EPSCs in T-stellate cells were on average significantly larger than under control conditions $(p=0.015)$. $C$, In the presence of TTX, PAPA NONOate increased the frequency, but not the amplitude, of EPSCs. Ca, T-stellate cell had spontaneous mEPSCs in the presence of TTX. $\boldsymbol{C} \boldsymbol{b}$, In the continued presence of TTX, PAPA NONOate evoked more rapid EPSCs. Cc, The amplitude distribution of EPSCs was not significantly different in the presence and absence of PAPA NONOate $(p=0.93)$. $\boldsymbol{D}$, The increase in EPSC frequency caused by the application of PAPA NONOate in 7 cells was significant.

\section{Potentiation depends on NO signaling}

Interconnections between T-stellate cells were generally detected only after strong depolarization of the postsynaptic cell was paired with presynaptic firing. Furthermore, potentiation manifested itself as an increase in the probability of observing a synaptic response. Postsynaptic depolarization can influence the probability of release only through a retrograde signal. We therefore tested whether NO plays a role in signaling in the VCN.

Application of NO donors provides a test of whether NO signaling plays a role and allows comparisons to be made of the action of $\mathrm{NO}$ on the three major groups of principal cells. We applied NO to slices through a donor whose release of NO occurs over an appropriate time range (Bradley and Steinert, 2015). To record from bushy cells, coronal slices were taken more anteriorly than those used to record from T-stellate cells. Bushy cells were identified electrophysiologically by their transient firing at the onset of a depolarizing current pulse with up to six action potentials and by hyperpolarizations that sagged slowly back to rest (Cao et al., 2007; Cao and Oertel, 2010, 2017). Octopus cells were recorded from caudal coronal sections of the VCN. They were identified electrophysiologically by their low input resistances, firing of only a single, small action potential at the onset of a depolarization, and hyperpolarizations that sagged quickly and strongly back toward rest (Golding et al., 1995; Bal and Oertel, 2000, 2001). The application of 100 or $300 \mu \mathrm{M}$ propylaminepropylamine NONOate (PAPA NONOate) evoked EPSCs in $11 / 11 \mathrm{~T}$-stellate cells tested, but at $300 \mu \mathrm{M}$, had no effect on bushy or octopus cells (Fig. 4A). The distribution of sizes of EPSCs before and after the addition of PAPA NONOate was statistically different ( $p=0.015$, Mann-Whitney $U$ test $)$ in T-stellate cells but was not significantly different in bushy $(p=0.5)$ and octopus $(p=0.9)$ cells (Fig. 4B). If the EPSCs in T-stellate cells evoked by 
PAPA NONOate were to have arisen from auditory nerve fibers, then such EPSCs would presumably be observed in other targets of auditory nerve fibers, the bushy and octopus cells. These findings are consistent with the conclusion that EPSCs in T-stellate cells that are evoked by PAPA NONOate are not associated with inputs that are common to all three types of principal cells, but rather to inputs that are associated specifically with T-stellate cells. Although it seems more likely that PAPA NONOate evokes EPSCs from interneurons and/or an interconnected network, we cannot exclude the possibility that auditory nerve synapses signal differently to different targets.

In the presence of $1 \mu \mathrm{M}$ TTX, PAPA NONOate evoked EPSCs in T-stellate cells whose amplitude did not differ from mEPSCs (Fig. $4 \mathrm{Ca}-\mathrm{Cc}$ ). The amplitude of mEPSCs measured in the presence of TTX was $60.8 \pm 24.2 \mathrm{pA}$. In the combined presence of TTX and PAPA NONOate, the amplitude of EPSCs was not different, $61.0 \pm 23.8(p=0.93)$. The frequency of mEPSCs was, however, increased (Fig. 4D). This experiment shows that the large EPSCs evoked in T-stellate cells by PAPA NONOate involve the spiking of neurons, reinforcing the notion that T-stellate cells are involved in a local neuronal network. This experiment also indicates that at least some presynaptic terminals that contact T-stellate cells are sensitive to NO and likely contain NO-GC.

In T-stellate cells, application of PAPA NONOate altered the distribution of EPSCs toward larger amplitudes, evoking some EPSCs with peak amplitudes of $1.4 \mathrm{nA}$. The amplitudes of EPSCs evoked by PAPA NONOate encompassed a range similar to that of EPSCs evoked by pairing activation of connected T-stellate cells (Figs. $3 B, 4 B$ ). In some cells, the amplitudes of PAPA NONOate-evoked EPSCs were variable (Fig. $4 A$ ), whereas in others evoked EPSCs were of uniform magnitude (Fig. 5A).

NO has been shown to affect voltage-gated ion channels and thereby to change the electrical excitability of neurons. NO slows and shifts the voltage sensitivity of HCN1-mediated $I_{\mathrm{h}}$ currents in the hyperpolarizing direction, suppressing $I_{\mathrm{h}}$, and it shifts the voltage sensitivity of HCN2-mediated $I_{\mathrm{h}}$ in the depolarizing direction, facilitating $I_{\mathrm{h}}$ (Kopp-Scheinpflug et al., 2015). $I_{\mathrm{h}}$ measured in somata of T-stellate cells, mediated by channels that contain HCN1 and HCN2 subunits (Koch et al., 2004; Cao and Oertel, 2011), is relatively slow and its voltage sensitivity is relatively negative (Fujino and Oertel, 2001; Rodrigues and Oertel, 2006). PAPA NONOate caused a change in resting potential of 1 $\mathrm{mV}$ ( $3 / 3$ cells tested) but had no other detectable effect. Resting potentials were not significantly different $(p=0.65)$ under control conditions $(-65.1 \pm 2.5 \mathrm{mV})$ and in the presence of PAPA NONOate $(-65.4 \pm 2.4 \mathrm{mV})$; input resistances were also not significantly different $(p=0.47)$ under control conditions $(93.6 \pm 17.0 \mathrm{M} \Omega)$ and in the presence of PAPA NONOate $(93.3 \pm 17.3)$. NO and synaptic activation of neurons also suppresses Kv3-mediated repolarizing currents and enhances Kv2mediated currents with the result that action potentials are broadened (Steinert et al., 2011). Neither the breadth nor the thresholds of action potentials was changed by the application of NO donors in T-stellate cells $(n=3)$. The widths at halfheight were $0.536 \pm 0.051 \mathrm{~ms}$ before and $0.533 \pm 0.064 \mathrm{~ms}$ after the application of PAPA NONOate. It is conceivable that NO shifts the electrical excitability in parts of the circuit from which we cannot record, such as terminals of T-stellate cells or of interneurons.

T-stellate cells have NMDA receptors that can initiate signaling (Ferragamo et al., 1998; Boehning and Snyder, 2003; Cao and Oertel, 2010). Figure $5 B$ shows that blocking NMDA receptors with $100 \mu \mathrm{M}$ (2R)-amino-5-phosphonovaleric acid (APV), a blocker of NMDA receptors (Biscoe et al., 1977), reversibly blocked potentiation in T-stellate cells. In a dual recording from T-stellate cells, initially no EPSCs were detected even when the presynaptic cell was driven to fire at 20 action potentials/s. After depolarizing the postsynaptic cell to $+30 \mathrm{mV}$ (Fig. $5 B b^{\star}$, inset), EPSCs were evoked at 4/s and faded over $1 \mathrm{~min}$. In the presence of APV, subsequent application of the pairing protocol evoked no EPSCs but after washing away the APV, pairing again induced potentiation. APV blocked potentiation in $3 / 3$ pairs tested.

The action of APV on EPSCs induced by the pairing protocol suggested that the responses include a substantial NMDA receptor-mediated component. In 5/12 cells, fast and slow components such as those illustrated in Figure $5 B b$ were evident in reversed EPSCs at $+30 \mathrm{mV}$; in other cells, the traces were too noisy to resolve slow components. APV reversibly abolished slow components of reversed EPSCs (Fig. $5 B c, B d$ ). The absence of slow components at $-65 \mathrm{mV}$ is also consistent with their being mediated by NMDA receptors that are known be blocked at negative potentials by $\mathrm{Mg}^{2+}$ (Mayer et al., 1984; Nowak et al., 1984).

We also tested whether potentiation is sensitive to a blocker of nitric oxide synthase, NG-nitro-L-argenine methyl ester (LNAME) (Pfeiffer et al., 1996). In all three cells tested, the application of $100 \mu \mathrm{M}$ L-NAME did indeed prevent the appearance of EPSCs of uniform amplitude after pairing of presynaptic firing with postsynaptic depolarization to $+30 \mathrm{mV}$ (Fig. 5C). Our conclusions are summarized diagrammatically in Figure $5 D$ based on the signaling pathway elucidated in the cerebellum that depends on the high-affinity binding of NO to guanylate cyclase (NO-GC) (Boehning and Snyder, 2003) (Fig. 5D). Pharmacological experiments support the conclusion that dendrites of T-stellate cells can generate $\mathrm{NO}$ and that terminals that contact T-stellate cells sense NO even in the presence of TTX and thus likely contain NO-GC. We do not know whether NO signaling occurs at synapses between presynaptic T-stellate cells and interneurons.

It seemed possible that a comparison of the shapes of EPSCs could differentiate sources of input to T-stellate cells. Figure $6 \mathrm{~A}$ shows that the time courses of a potentiated EPSC (red) and a unitary EPSC evoked by a minimal stimulation of an adjacent fiber bundle (thick black) (Cao and Oertel, 2010) were similar. EPSCs evoked by the application of PAPA NONOate (green traces) were varied both in amplitude and in time course. Some resembled potentiated EPSCs and minimal responses to shocks (Fig. 6A, yellow green). Others were larger and broader (Fig. 6A, bright and dark greens). The differences in time course are clearer in Figure $6 A b$, where traces were normalized in amplitude and aligned in time to where they had risen to $50 \%$ amplitude. The breadth and amplitude of the large EPSCs suggest that they could reflect the summation of slightly asynchronous EPSCs. One possible explanation of these findings is that cells had multiple NO-sensitive inputs that impinged nearly synchronously. Although this observation was made in only two cells, it could reflect activity of a network that is disrupted in most slices. On average, EPSCs evoked in T-stellate cells by differing means did not differ either in time course or in the amplitude (Fig. 6B). There was greater variability in the size of EPSCs evoked by the application of PAPA NONOate than in the size of potentiated and unitary, shockevoked EPSCs (Figs. 3B, 4B) (Cao and Oertel, 2010).

\section{Localization of molecular components of NO signaling}

The electrophysiological findings make several predictions that are summarized in the model shown in Figure $5 D$. The finding 


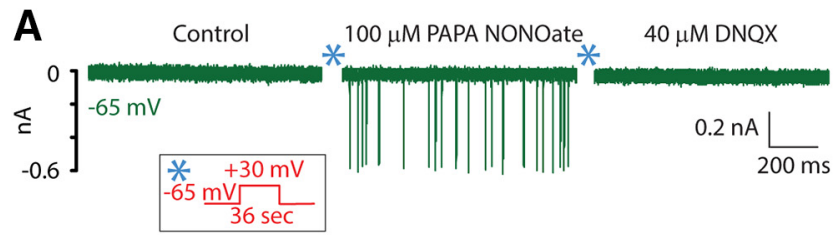

B
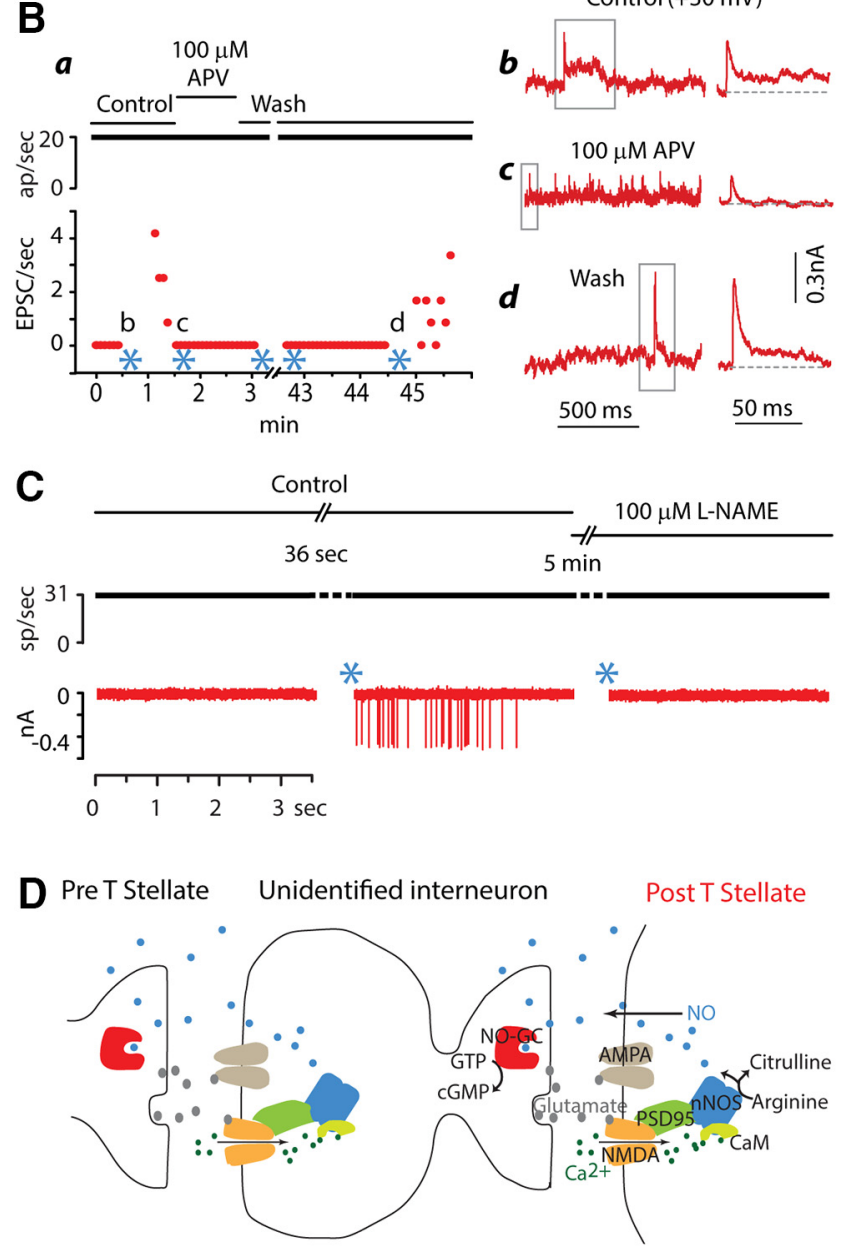

Figure 5. Pharmacological studies support a role of $\mathrm{NO}$ signaling in potentiation of interconnections between T-stellate cells. $A$, Application of an NO donor, PAPA NONOate, mimicked potentiation in T-stellate cells. It evoked EPSCs of approximately uniform amplitude that were mediated through AMPA receptors. $\boldsymbol{B}$, Potentiation requires NMDA receptors. $\boldsymbol{B} \boldsymbol{a}$, Plot summarizes one dual recording. The presynaptic cell fired constantly throughout the experiment. Initially no EPSCs were observed. After pairing presynaptic firing with postsynaptic depolarization $(*)$, EPSCs were initially rapid and over $\sim 1 \mathrm{~min}$, the frequency dropped. The application of APV blocked potentiation and also reversibly eliminated slow components of EPSCs visible while the cell was depolarized to $+30 \mathrm{mV}$. $\boldsymbol{B} \boldsymbol{b}-\boldsymbol{B} \boldsymbol{d}$, Traces on the left, shown after smoothing, were recorded while the cell was depolarized to $+30 \mathrm{mV}$ at the times indicated in $\mathbf{a}$. During depolarization to $+30 \mathrm{mV}$, EPSCs were reversed. Panels on the right show EPSCs marked by gray boxes on the left at expanded time scales. EPSCs had early rapid components that were sometimes followed by a slower component $(\boldsymbol{B} \boldsymbol{b}, \boldsymbol{B} \boldsymbol{d})$. In the presence of of APV, the rapid phases remained but no long EPSCs were observed $(\boldsymbol{B C})$. C, Potentiation depended on nNOS. Pairing of presynaptic firing at $33 / \mathrm{s}$ with a postsynaptic depolarization to $+30 \mathrm{mV}$ for $36 \mathrm{~s}\left({ }^{*}\right)$ evoked EPSCs. The subsequent addition to the bath of L-NAME, NG-nitro-L-argenine methyl ester, a blocker of nNOS, prevented potentiation. This experiment was repeated in 3 cells. $\boldsymbol{D}$, These results are consistent with potentiation being mediated through a signaling pathway such as that proposed by Boehning and Snyder (Boehning and Snyder, 2003). Release of glutamate from presynaptic terminals activates postsynaptic AMPA and NMDA receptors. $\mathrm{Ca}^{2+}$ entering through NMDA receptors binds calmodulin (CaM) which in turn activates neuronal nitric oxide synthase (nNOS). nNOS converts arginine to citrulline and NO. Being a small gas, NO diffuses not just within the cell but also through the membrane to adjacent cells. The NO receptor guanylate cyclase (NO-GC) in presynaptic terminals detects NO and raises levels of CGMP. Whether NO signaling acts at only one of the synapses or at all synapses in a polysynaptic
A

A $a$

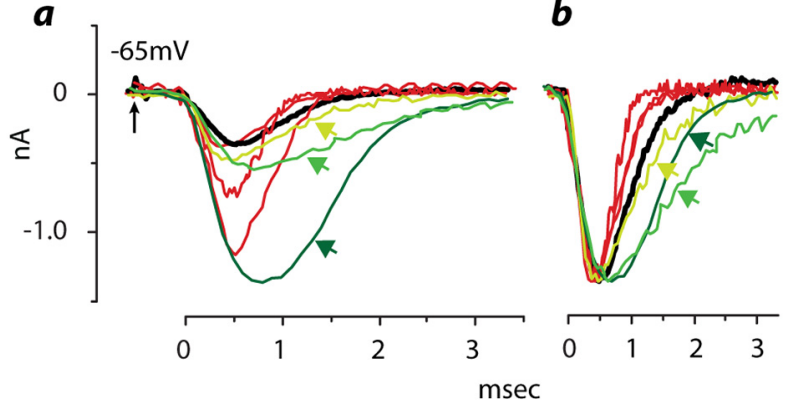

B

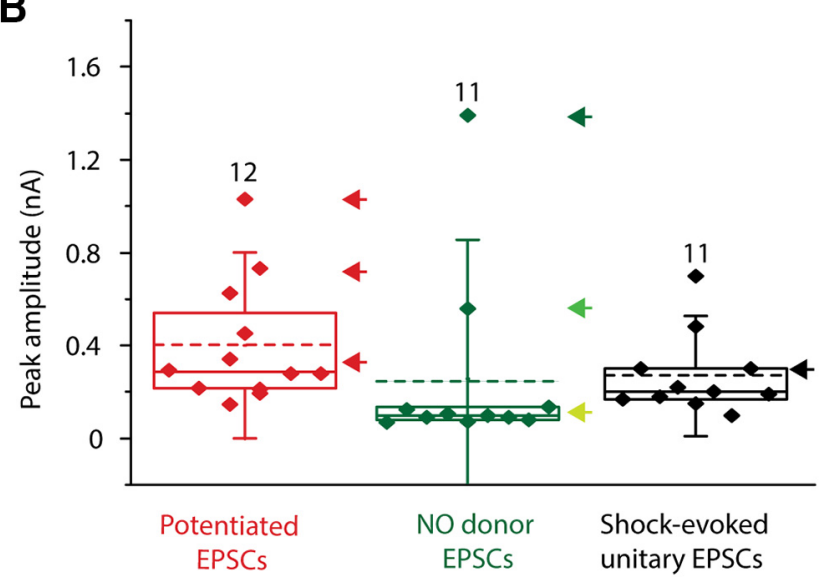

Figure 6. EPSCS evoked by potentiation (red), by the application of an NO donor (green), and by a shock to a bundle of auditory nerve fibers that is just strong enough to evoke a response (black) are compared. $\boldsymbol{A a}$, Superposition of EPSCs evoked in differing ways allows their kinetics to be compared. EPSCs evoked by shocks (thick black), by potentiation (red) and some of those evoked by an NO donor (yellow green) are similar. In a few cells, EPSCs evoked by the NO donor were broader and larger than the others (bright green, dark green). $\boldsymbol{A} \boldsymbol{b}$, Those same traces are normalized and aligned at the halfway point of the rise of the EPSCS, showing that in two cells the EPSCs evoked by the application of NO were broader and slower than most EPSCS (bright green and dark green). B, Plot compares amplitudes of EPSCs evoked in the three ways. Each point represents the average amplitude of EPSCs in one cell. The dashed lines show the mean of those mean amplitudes, the solid lines show the median, boxes enclose the $25-75 \%$ range, and whiskers represent SD. The cells from which the traces in $\boldsymbol{A}$ were taken are marked with arrows whose color matches traces and arrows in Figure $6 A$.

that the application of NO donors evokes a change in frequency in mEPSCs in the presence of TTX predicts that the enzyme that synthesizes NO, nNOS, is present in the cell bodies and dendrites of T-stellate cells and that the receptor for NO, NO-GC, is expressed in synaptic terminals of interneurons. We know less about synapses between T-stellate cells and interneurons. The requirement for presynaptic firing of glutamatergic $\mathrm{T}$-stellate cells indicates that interneurons have AMPA and probably also NMDA receptors. Whether these synapses also use NO signaling is not resolved by our electrophysiological experiments. We thus undertook an immunohistochemical study to localize nNOS and NO-GC. These experiments were done on 9 mice of both sexes and aged between 3 and 6 weeks. We observed no differences in labeling between sexes or as a function of age.

In the absence of molecular markers of T-stellate cells, we depend on what is known about their distribution to make inter-

pathway is not known. Possibly NO generated at multiple synapses sums to influence other nearby synapses. $\mathrm{NO}$ can also act within the cell in which it is synthesized on targets with lower affinities to affect the trafficking of AMPA receptors (Bradley and Steinert, 2016). 


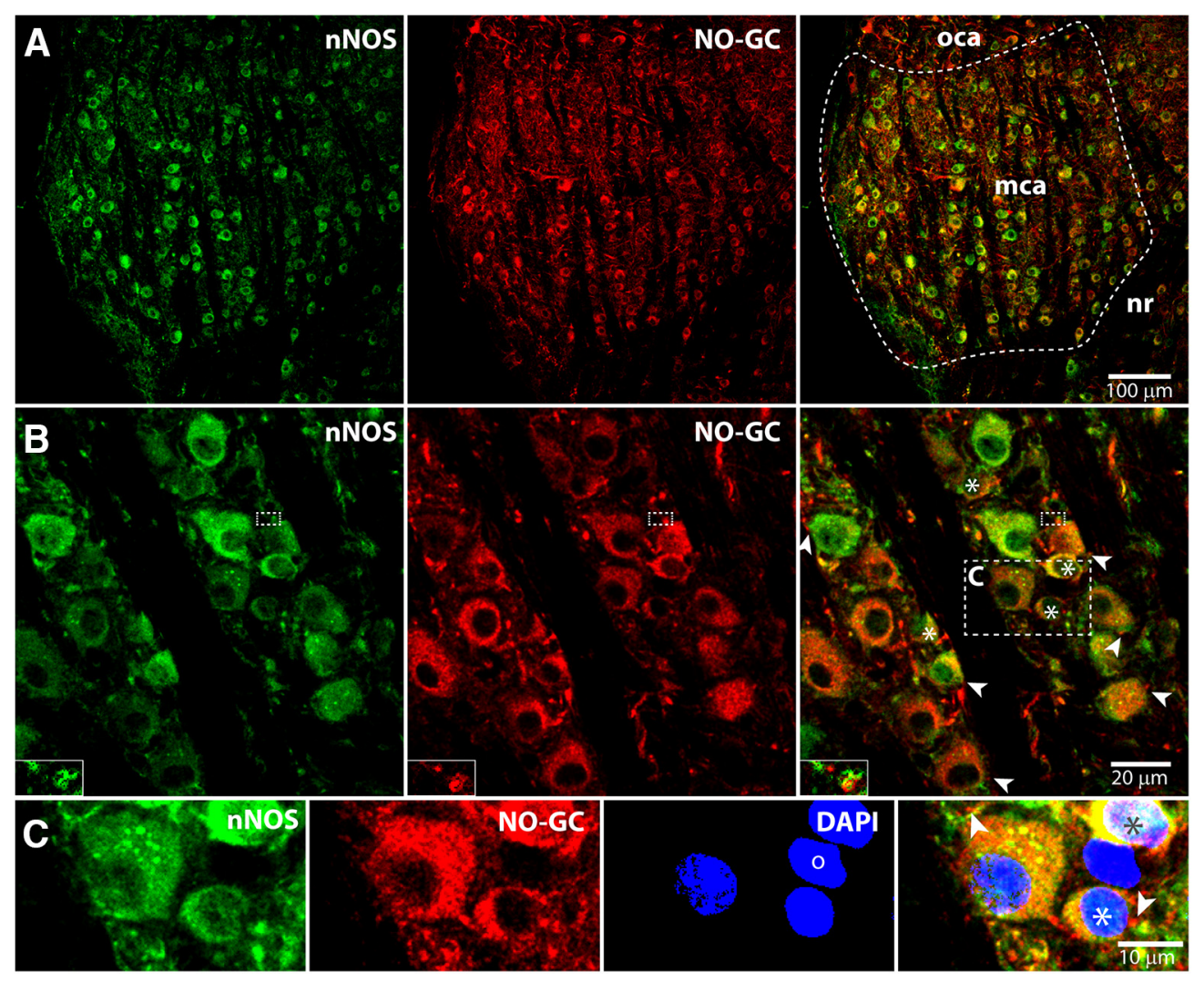

Figure 7. Enzymes that support NO signaling are present in the pVCN where T-stellate cells reside. $\boldsymbol{A}, Z$ projection of a $5 \mu \mathrm{m}$ stack of $0.8 \mu \mathrm{m}$ confocal images shows a sagittal section of the multipolar cell area ( $\mathrm{mca}$ ) of the pVCN with a small part of the octopus cell area (oca) and of the nerve root (nr) also visible. In the multipolar cell area, labeled cell bodies lie between fascicles of auditory nerve fibers. nNOS (green) and NO-GC (red) are coexpressed in most cell bodies (right). B, C, Z projection of a stack $(0.1 \mu \mathrm{m}, \sim 2.5 \mu \mathrm{m})$ from a section from another animal shows the labeling pattern at higher magnification. The brightness of labeling for both $\mathrm{nNOS}$ and NO-GC varies between cells. The right panel shows that large cell bodies, as well as small cell bodies (stars), are double labeled for nNOS and NO-GC. Puncta that are brightly labeled for NO-GC (arrowheads) can be observed apposing double-labeled large and small cell bodies. Insets in $\boldsymbol{B}$ are enlargements from single confocal images that show overlap of nNOS and NO-GC (yellow) in a punctum in the area outlined by small dashed boxes. The yellow color indicates that nNOS and NO-GC are close together. C, Enlargements of the area outlined in B showing NO-GC-labeled puncta apposed to both large and small cells. One DAPI-labeled (blue) neuron (0) was labeled for neither nNOS nor NO-GC.

pretations. T-stellate cells comprise most of the large neurons in the multipolar cell area of the pVCN (Adams, 1979; Oertel et al., 1990; Doucet and Ryugo, 1997). Using antibodies against NO-GC $\beta 1$ and against the C-terminal of nNOS, we find that most or all labeled larger cells coexpress both proteins (Fig. 7). In addition, some small cells interspersed between the large cells also coexpress nNOS and NO-GC (Fig. $7 B, C$ ). The brightness of labeling for both antigens and the relative intensities varied between cells. These findings are consistent with previously reported findings (Burette et al., 2001).

Synaptic terminals in the multipolar cell area appear as immunolabeled puncta, although puncta can also reflect cross sections of dendrites and axons. Terminals arise from auditory nerve fibers (Doucet and Ryugo, 1997; Cao et al., 2008), local collateral terminals of T- and D-stellate cells (Oertel et al., 1990; Doucet and Ryugo, 1997), newly discovered small glycinergic cells (Ngodup and Trussell, 2019), tuberculoventral cells (Zhang and Oertel, 1993), somatosensory afferents (Zeng et al., 2012), and possibly from unidentified excitatory neurons. NO-GC-positive puncta appose both large and small cells (Fig. 7 B, C, arrowheads, inset). The electrophysiological and pharmacological results predict that there exist NO-GC containing puncta apposed to nNOS containing cell bodies and dendrites (Boehning and Snyder, 2003). At the resolution of single confocal images, that apposition appears as overlap or partial overlap of nNOS and NO-GC in some puncta. An example of such a punctum that was on a pro- cess that was traced back to a large cell body in a stack of serial confocal images is shown in Figure $7 B$ (inset). We expect that NO-GC is expressed in terminals apposed to the soma and to distal dendrites of T-stellate cells, but these are difficult to resolve. Our findings raise the possibility that the target of NO is a separate population of small excitatory interneurons. The small size of the interneurons could account for why we have not observed monosynaptic interconnections onto T-stellate cells; our recordings were routinely from large cells. Nothing is known about the small, excitatory neurons in the multipolar cell area of the pVCN; they have not previously been described. Although it is our goal to learn more about these interneurons and to test whether they could mediate potentiation, those studies are beyond the scope of the present study.

The electrophysiological and immunohistochemical results are consistent with the small cells serving as the unidentified interneuron in the model presented in Figure $5 D$. According to this model, TTX-insensitive NO signaling potentiates synapses between interneurons and postsynaptic T-stellate cells. As the small cells express nNOS and T-stellate cells express NO-GC and NO-GC-positive puncta are found around small cells, NO signaling may well occur at synapses between presynaptic T-stellate cells and interneurons. It is also possible that NO spreads beyond the glutamatergic synapses to encompass a larger group of cells. 


\section{Discussion}

Coactivating T-stellate cells by pairing of presynaptic firing with postsynaptic depolarization increased the probability of EPSCs in the postsynaptic cell over periods of seconds to minutes, times longer than classical forms of short-term plasticity (Zucker and Regehr, 2002) and shorter than long-term plasticity (Malenka and Bear, 2004; Castillo, 2012). In every pair of T-stellate cells, EPSCs followed presynaptic firing with a variable latency, implying that connections were polysynaptic. Potentiation required retrograde signaling by $\mathrm{NO}$.

The time course and spatial extent of NO signaling are consistent with potentiation in T-stellate cells. Calcium rises and falls over tenths to tens of seconds to activate nNOS (Namiki et al., 2005; Mao et al., 2008; Burgess et al., 2016; Dal Maschio et al., 2017). In the present experiments, depolarization of a single $\mathrm{T}$-stellate cell determines whether connections are functional, showing that NO acts at the level of single neurons; it is possible that a cloud of NO could affect groups of cells and synapses (Edelman and Gally, 1992; Batchelor et al., 2010; Garthwaite, 2016). Direct measurements indicate that the concentration of NO falls rapidly and acts at synapses within about $20 \mu \mathrm{m}$ (Namiki et al., 2005). Linking the activity of neurons with local dilation of capillary blood vessels requires NO signaling between neurons and pericytes around capillaries that are $\sim 8 \mu \mathrm{m}$ away and occurs over seconds to minutes (Hall et al., 2014). High-affinity interactions with NO-GC have a wider reach than lower-affinity interactions through S-nitrosylation or 3-nitrotyrosination of synaptic proteins (Bradley and Steinert, 2015).

NO commonly acts via NO-GC by increasing cGMP and activating protein kinase $\mathrm{G}$ and cGMP-gated ion channels, but can also act directly on ion channels and proteins associated with synaptic signaling and with electrical excitability (Ahern et al., 2002; Boehning and Snyder, 2003; Bradley and Steinert, 2016). NO modulates the voltage-sensitivity of $I_{\mathrm{h}}$ through both cGMPdependent and -independent pathways (Kopp-Scheinflug et al., 2015). NO also modulates voltage-gated $\mathrm{K}^{+}$currents that regulate the width and threshold of action potentials (Steinert et al., 2008, 2011). Recordings from T-stellate cells showed no sign of changes to the input resistance, resting potentials, or shapes and thresholds of action potentials, suggesting that NO affects synaptic machinery rather than electrical excitability, but it is possible that NO alters the electrical excitability of distant terminals or interneurons. NO is implicated in potentiation in many parts of the brain, including the hippocampus (Zhuo et al., 1994; Castillo, 2012), cerebellum (Shin and Linden, 2005; Qiu and Knöpfel, 2007), and ventral tegmental area (Polter et al., 2018), and increases the quantal content of cholinergic efferent fibers in the cochlea (Kong et al., 2013) through signaling pathways that have not been completely elucidated. T-stellate cells contain NMDA receptors for regulating $\mathrm{Ca}^{2+}$ entry, nNOS for generating $\mathrm{NO}$, and NO-GC for detecting NO (Figs. 5, 7) (Burette et al., 2001; Cao and Oertel, 2010; Coomber et al., 2015).

Trains of shocks to auditory nerve fibers coactivate T-stellate cells and would be expected to potentiate interconnections between them. Potentiation has been observed in T-stellate cells in responses to trains of shocks to the auditory nerve, without being recognized as such (Ferragamo et al., 1998). Single shocks evoked EPSPs temporally locked to shocks and lasting $\sim 5 \mathrm{~ms}$ (Oertel, 1983; Wu and Oertel, 1984, 1987). Trains of shocks evoked not only the short-latency, temporally locked EPSPs, but also large, long, suprathreshold EPSPs that evoked action potentials hundreds of milliseconds after the end of a train of shocks (Ferragamo et al., 1998). In vivo, auditory nerve fibers fire spontaneously so that acoustic input is likely to modulate potentiation upward and downward.

Interconnections between T-stellate cells in dual recordings were polysynaptic and bidirectional. Two findings indicate that these interconnections reflect firing in a network. First, before the addition of TTX, PAPA NONOate evoked large EPSCs, whereas after TTX was added, the PAPA NONOate increased the frequency of mEPSCs. Second, two T-stellate cells responded to NO donors with EPSCs that were larger and broader than EPSCs evoked by the stimulation of one presynaptic cell in dual recordings (Fig. 6A, bright green and dark green), suggesting that multiple, nearly synchronous, NO-sensitive EPSCs sum. In our experiments, where some connections were cut, the network involved a relatively small number of interneurons because the EPSCs were uniform in amplitude and were not observed to sum.

Understanding signaling between T-stellate cells is complicated by the presence of interneurons about which we know little. We envision the following events (Fig. 5D). Under resting conditions, action potentials in the presynaptic T-stellate cell presumably generate unitary, subthreshold EPSPs in the interneuron that are not conveyed to the postsynaptic T-stellate cell. By generating long-lasting, NMDA-receptor-dependent EPSPs, continued rapid firing in the presynaptic cell could produce suprathreshold responses in the interneuron that are not temporally locked with the inputs. (Increasing electrical excitability of the interneuron would likely produce action potentials in the interneurons that are temporally locked to their inputs.) The firing of the interneuron is indicated by EPSCs in the postsynaptic T-stellate cell. Once the interneuron begins to fire, the synapse between the interneuron and the depolarized, postsynaptic T-stellate cell becomes potentiated.

There are several reasons to think that the networks that connect T-stellate cells are aligned along isofrequency laminae, although none is conclusive. First, the observed interconnections were between pairs of cells that were aligned between fascicles of auditory nerve fibers, whereas pairs of T-stellate cells that were not connected were less clearly aligned. Second, the collateral terminals of T-stellate cells are aligned with dendrites, parallel to auditory nerve fibers in mice and cats (Wu and Oertel, 1984; Smith and Rhode, 1989; Oertel et al., 1990, 2011). Their morphology suggests that T-stellate cells and their targets are coactivated by a small number of similarly tuned auditory nerve fibers. Third, if excitatory interneurons in the multipolar cell area were to spread across isofrequency laminae, then they would presumably widen isofrequency laminae and smear the tonotopic organization (Rhode and Smith, 1986; Blackburn and Sachs, 1989; Palmer et al., 1996). Known neuronal circuits in the cochlear nuclei, for example sideband inhibition, sharpen frequency tuning (Caspary et al., 1994; Rhode and Greenberg, 1994).

T-stellate cells fire steadily at rates that increase monotonically with the intensity of sounds for as long as acoustic energy falls within their narrow frequency tuning range, making them well suited to conveying information about the spectrum of sounds. The regularity and consistency of firing in responses to tones generates "chopping" peristimulus time histograms (Rhode et al., 1983; Blackburn and Sachs, 1989; Smith and Rhode, 1989; Palmer et al., 2003; Oertel et al., 2011). Our findings could explain why "choppers" encode spectral peaks more clearly and over a wider dynamic range than auditory nerve fibers with high spontaneous firing rates or other VCN neurons (Blackburn and Sachs, 1990; May et al., 1998). Those choppers tuned to spectral 
peaks fire most vigorously and would be expected to experience the strongest potentiation that in turn could enhance the encoding of spectral peaks. That enhancement would be slow, perhaps compensating for the slowing of firing of auditory nerve fibers with adaptation. In cats, choppers are contacted by fibers with both low and high spontaneous firing rates (Liberman, 1993). Fibers with low spontaneous firing rates have wider dynamic ranges than those with high spontaneous firing rates, and could also broaden the dynamic range in their targets. In mice, the distribution of spontaneous firing rates is less clearly grouped than in cats (Taberner and Liberman, 2005).

Our findings could also explain why T-stellate cells become hyperexcitable in the face of hearing loss (Cai et al., 2009; Vogler et al., 2011; Coomber et al., 2015). As T-stellate cells lose input from the auditory nerve, their main source of excitation (Cant, 1981; Alibardi, 1998; Ferragamo et al., 1998; Cao and Oertel, 2010), homeostatic mechanisms would be expected to strengthen remaining excitatory inputs (Turrigiano, 1999, 2008), including those from excitatory interneurons. Furthermore, hearing loss increases nNOS expression in T-stellate cells, suggesting that potentiation by $\mathrm{NO}$ signaling itself is strengthened. In animals that were unilaterally subjected to acoustic trauma and that were shown behaviorally to have tinnitus, labeling for nNOS in stellate cells was more intense than in animals without tinnitus (Coomber et al., 2014, 2015). Hearing loss, like the application of PAPA NONOate, increases the frequency of mEPSCs (Rich et al., 2010). Hearing loss also uncouples excitation and inhibition. Normally auditory nerve fibers drive both excitatory and inhibitory neurons, but if auditory nerve fiber inputs are lost, then excitation and inhibition are no longer activated together (Oertel et al., 1990; Wickesberg and Oertel, 1990; Zhang and Oertel, 1993; Ferragamo et al., 1998). Plastic, bidirectional interconnections between T-stellate cells could serve as a central gain control in normal hearing. In the face of hearing loss, these same mechanisms can generate hyperexcitability and perhaps tinnitus.

\section{References}

Adams JC (1979) Ascending projections to the inferior colliculus. J Comp Neurol 183:519-538.

Ahern GP, Klyachko VA, Jackson MB (2002) cGMP and S-nitrosylation: two routes for modulation of neuronal excitability by NO. Trends Neurosci 25:510-517.

Alibardi L (1998) Ultrastructural and immunocytochemical characterization of neurons in the rat ventral cochlear nucleus projecting to the inferior colliculus. Ann Anat 180:415-426.

Bal R, Oertel D (2000) Hyperpolarization-activated, mixed-cation current $\left(I_{\mathrm{h}}\right)$ in octopus cells of the mammalian cochlear nucleus. J Neurophysiol 84:806-817.

Bal R, Oertel D (2001) Potassium currents in octopus cells of the mammalian cochlear nucleus. J Neurophysiol 86:2299-2311.

Batchelor AM, Bartus K, Reynell C, Constantinou S, Halvey EJ, Held KF, Dostmann WR, Vernon J, Garthwaite J (2010) Exquisite sensitivity to subsecond, picomolar nitric oxide transients conferred on cells by guanylyl cyclase-coupled receptors. Proc Natl Acad Sci U S A 107:22060-22065.

Biscoe TJ, Davies J, Dray A, Evans RH, Francis AA, Martin MR, Watkins JC (1977) Depression of synaptic excitation and of amino acid-induced excitatory responses of spinal cord neurones by D-alpha-aminoadipate, alpha,epsilon-diaminopimelic acid and HA-966. Eur J Pharmacol 45: 315-316.

Blackburn CC, Sachs MB (1989) Classification of unit types in the anteroventral cochlear nucleus: PST histograms and regularity analysis. J Neurophysiol 62:1303-1329.
Blackburn CC, Sachs MB (1990) The representations of the steady-state vowel sound phoneme-E in the discharge patterns of cat anteroventral cochlear nucleus neurons. J Neurophysiol 63:1191-1212.

Boehning D, Snyder SH (2003) Novel neural modulators. Annu Rev Neurosci 26:105-131.

Bradley SA, Steinert JR (2015) Characterisation and comparison of temporal release profiles of nitric oxide generating donors. J Neurosci Methods 245:116-124.

Bradley SA, Steinert JR (2016) Nitric oxide-mediated posttranslational modifications: impacts at the synapse. Oxid Med Cell Longev 2016: 5681036.

Bredt DS, Snyder SH (1992) Nitric oxide, a novel neuronal messenger. Neuron 8:3-11.

Burette A, Petrusz P, Schmidt HH, Weinberg RJ (2001) Immunohistochemical localization of nitric oxide synthase and soluble guanylyl cyclase in the ventral cochlear nucleus of the rat. J Comp Neurol 431:1-10.

Burgess CR, Ramesh RN, Sugden AU, Levandowski KM, Minnig MA, Fenselau H, Lowell BB, Andermann ML (2016) Hunger-dependent enhancement of food cue responses in mouse postrhinal cortex and lateral amygdala. Neuron 91:1154-1169.

Cai S, Ma WL, Young ED (2009) Encoding intensity in ventral cochlear nucleus following acoustic trauma: implications for loudness recruitment. J Assoc Res Otolaryngol 10:5-22.

Cant NB (1981) The fine structure of two types of stellate cells in the anterior division of the anteroventral cochlear nucleus of the cat. Neuroscience 6:2643-2655.

Cao XJ, Oertel D (2010) Auditory nerve fibers excite targets through synapses that vary in convergence, strength, and short-term plasticity. J Neurophysiol 104:2308-2320.

Cao XJ, Oertel D (2011) The magnitudes of hyperpolarization-activated and low-voltage-activated potassium currents co-vary in neurons of the ventral cochlear nucleus. J Neurophysiol 106:630-640.

Cao XJ, Oertel D (2017) Genetic perturbations suggest a role of the resting potential in regulating the expression of the ion channels of the KCNA and HCN families in octopus cells of the ventral cochlear nucleus. Hear Res 345:57-68.

Cao XJ, Shatadal S, Oertel D (2007) Voltage-sensitive conductances of bushy cells of the mammalian ventral cochlear nucleus. J Neurophysiol 97:3961-3975.

Cao XJ, McGinley MJ, Oertel D (2008) Connections and synaptic function in the posteroventral cochlear nucleus of deaf jerker mice. J Comp Neurol 510:297-308.

Caspary DM, Backoff PM, Finlayson PG, Palombi PS (1994) Inhibitory inputs modulate discharge rate within frequency receptive-fields of anteroventral cochlear nucleus neurons. J Neurophysiol 72:2124-2133.

Castillo PE (2012) Presynaptic LTP and LTD of excitatory and inhibitory synapses. Cold Spring Harb Perspect Biol 4:a005728.

Coomber B, Berger JI, Kowalkowski VL, Shackleton TM, Palmer AR, Wallace MN (2014) Neural changes accompanying tinnitus following unilateral acoustic trauma in the guinea pig. Eur J Neurosci 40:2427-2441.

Coomber B, Kowalkowski VL, Berger JI, Palmer AR, Wallace MN (2015) Modulating central gain in tinnitus: changes in nitric oxide synthase in the ventral cochlear nucleus. Front Neurol 6:53.

Dal Maschio M, Donovan JC, Helmbrecht TO, Baier H (2017) Linking neurons to network function and behavior by two-photon holographic optogenetics and volumetric imaging. Neuron 94:774-789.e5.

Doucet JR, Ryugo DK (1997) Projections from the ventral cochlear nucleus to the dorsal cochlear nucleus in rats. J Comp Neurol 385:245-264.

Drayton M, Noben-Trauth K (2006) Mapping quantitative trait loci for hearing loss in black swiss mice. Hear Res 212:128-139.

Edelman GM, Gally JA (1992) Nitric oxide: linking space and time in the brain. Proc Natl Acad Sci U S A 89:11651-11652.

Ferragamo MJ, Golding NL, Oertel D (1998) Synaptic inputs to stellate cells in the ventral cochlear nucleus. J Neurophysiol 79:51-63.

Frisina RD, Smith RL, Chamberlain SC (1990) Encoding of amplitude modulation in the gerbil cochlear nucleus: I. A hierarchy of enhancement. Hear Res 44:99-122.

Fujino K, Oertel D (2001) Cholinergic modulation of stellate cells in the mammalian ventral cochlear nucleus. J Neurosci 21:7372-7383.

Furchgott RF, Jothianandan D (1991) Endothelium-dependent and -independent vasodilation involving cyclic GMP: relaxation induced by nitric oxide, carbon monoxide and light. Blood Vessels 28:52-61. 
Gardner SM, Trussell LO, Oertel D (1999) Time course and permeation of synaptic AMPA receptors in cochlear nuclear neurons correlate with input. J Neurosci 19:8721-8729.

Garthwaite J (2016) From synaptically localized to volume transmission by nitric oxide. J Physiol 594:9-18.

Garthwaite J, Charles SL, Chess-Williams R (1988) Endothelium-derived relaxing factor release on activation of NMDA receptors suggests role as intercellular messenger in the brain. Nature 336:385-388.

Golding NL, Robertson D, Oertel D (1995) Recordings from slices indicate that octopus cells of the cochlear nucleus detect coincident firing of auditory-nervefibers with temporal precision. J Neurosci 15:3138-3153.

Hall CN, Reynell C, Gesslein B, Hamilton NB, Mishra A, Sutherland BA, O’Farrell FM, Buchan AM, Lauritzen M, Attwell D (2014) Capillary pericytes regulate cerebral blood flow in health and disease. Nature 508:55-60.

Isaac JT, Nicoll RA, Malenka RC (1995) Evidence for silent synapses: implications for the expression of LTP. Neuron 15:427-434.

Koch U, Braun M, Kapfer C, Grothe B (2004) Distribution of HCN1 and HCN2 in rat auditory brainstem nuclei. Eur J Neurosci 20:79-91.

Kong JH, Zachary S, Rohmann KN, Fuchs PA (2013) Retrograde facilitation of efferent synapses on cochlear hair cells. J Assoc Res Otolaryngol 14:1727.

Kopp-Scheinpflug C, Pigott BM, Forsythe ID (2015) Nitric oxide selectively suppresses IH currents mediated by HCN1-containing channels. J Physiol 593:1685-1700

Kujawa SG, Liberman MC (2009) Adding insult to injury: cochlear nerve degeneration after "temporary" noise-induced hearing loss. J Neurosci 29:14077-14085.

Laudanski J, Coombes S, Palmer AR, Sumner CJ (2010) Mode-locked spike trains in responses of ventral cochlear nucleus chopper and onset neurons to periodic stimuli. J Neurophysiol 103:1226-1237.

Liao D, Hessler NA, Malinow R (1995) Activation of postsynaptically silent synapses during pairing-induced LTP in CA1 region of hippocampal slice. Nature 375:400-404.

Liberman MC (1993) Central projections of auditory nerve fibers of differing spontaneous rate, II: posteroventral and dorsal cochlear nuclei. J Comp Neurol 327:17-36.

Malenka RC, Bear MF (2004) LTP and LTD: an embarrassment of riches. Neuron 44:5-21.

Mao T, O'Connor DH, Scheuss V, Nakai J, Svoboda K (2008) Characterization and subcellular targeting of GCaMP-type genetically-encoded calcium indicators. PLoS One 3:e1796.

May BJ, Prell GS, Sachs MB (1998) Vowel representations in the ventral cochlear nucleus of the cat: effects of level, background noise, and behavioral state. J Neurophysiol 79:1755-1767.

Mayer ML, Westbrook GL, Guthrie PB (1984) Voltage-dependent block by $\mathrm{Mg} 2+$ of NMDA responses in spinal cord neurones. Nature 309:261-263.

Namiki S, Kakizawa S, Hirose K, Iino M (2005) NO signalling decodes frequency of neuronal activity and generates synapse-specific plasticity in mouse cerebellum. J Physiol 566:849-863.

Ngodup T, Trussell, LO (2019) Discovery of a novel inhibitory cell type in the cochlear nucleus. ARO Abstracts 42:PS14. Available at https://cdn. ymaws.com/www.aro.org/resource/resmgr/mwm2019/2019_aro_mwm_ abstracts_final.pdf

Nowak L, Bregestovski P, Ascher P, Herbet A, Prochiantz A (1984) Magnesium gates glutamate-activated channels in mouse central neurones. Nature 307:462-465.

Oertel D (1983) Synaptic responses and electrical properties of cells in brain slices of the mouse anteroventral cochlear nucleus. J Neurosci 3: 2043-2053.

Oertel D, Wu SH, Garb MW, Dizack C (1990) Morphology and physiology of cells in slice preparations of the posteroventral cochlear nucleus of mice. J Comp Neurol 295:136-154.

Oertel D, Wright S, Cao XJ, Ferragamo M, Bal R (2011) The multiple functions of T stellate/multipolar/chopper cells in the ventral cochlear nucleus. Hear Res 276:61-69.

Palmer AR, Jiang D, Marshall DH (1996) Responses of ventral cochlear nucleus onset and chopper units as a function of signal bandwidth. J Neurophysiol 75:780-794.

Palmer AR, Wallace MN, Arnott RH, Shackleton TM (2003) Morphology of physiologically characterised ventral cochlear nucleus stellate cells. Exp Brain Res 153:418-426.
Pfeiffer S, Leopold E, Schmidt K, Brunner F, Mayer B (1996) Inhibition of nitric oxide synthesis by NG-nitro-L-arginine methyl ester (L-NAME): requirement for bioactivation to the free acid, NG-nitro-L-arginine. $\mathrm{Br} J$ Pharmacol 118:1433-1440.

Polter AM, Barcomb K, Tsuda AC, Kauer JA (2018) Synaptic function and plasticity in identified inhibitory inputs onto VTA dopamine neurons. Eur J Neurosci 47:1208-1218.

Qiu DL, Knöpfel T (2007) An NMDA receptor/nitric oxide cascade in presynaptic parallel fiber-Purkinje neuron long-term potentiation. J Neurosci 27:3408-3415.

Rhode WS, Greenberg S (1994) Lateral suppression and inhibition in the cochlear nucleus of the cat. J Neurophysiol 71:493-514.

Rhode WS, Smith PH (1986) Encoding timing and intensity in the ventral cochlear nucleus of the cat. J Neurophysiol 56:261-286.

Rhode WS, Oertel D, Smith PH (1983) Physiological response properties of cells labeled intracellularly with horseradish peroxidase in cat ventral cochlear nucleus. J Comp Neurol 213:448-463.

Rich AW, Xie R, Manis PB (2010) Hearing loss alters quantal release at cochlear nucleus stellate cells. Laryngoscope 120:2047-2053.

Rodrigues AR, Oertel D (2006) Hyperpolarization-activated currents regulate excitability in stellate cells of the mammalian ventral cochlear nucleus. J Neurophysiol 95:76-87.

Sattler R, Xiong Z, Lu WY, Hafner M, MacDonald JF, Tymianski M (1999) Specific coupling of NMDA receptor activation to nitric oxide neurotoxicity by PSD-95 protein. Science 284:1845-1848.

Schofield BR, Mellott JG, Motts SD (2014) Subcollicular projections to the auditory thalamus and collateral projections to the inferior colliculus. Front Neuroanat 8:70.

Sergeyenko Y, Lall K, Liberman MC, Kujawa SG (2013) Age-related cochlear synaptopathy: an early-onset contributor to auditory functional decline. J Neurosci 33:13686-13694.

Shannon RV, Zeng FG, Kamath V, Wygonski J, Ekelid M (1995) Speech recognition with primarily temporal cues. Science 270:303-304.

Shin JH, Linden DJ (2005) An NMDA receptor/nitric oxide cascade is involved in cerebellar LTD but is not localized to the parallel fiber terminal. J Neurophysiol 94:4281-4289.

Smith PH, Rhode WS (1989) Structural and functional properties distinguish two types of multipolar cells in the ventral cochlear nucleus. J Comp Neurol 282:595-616.

Steinert JR, Kopp-Scheinpflug C, Baker C, Challiss RA, Mistry R, Haustein MD, Griffin SJ, Tong H, Graham BP, Forsythe ID (2008) Nitric oxide is a volume transmitter regulating postsynaptic excitability at a glutamatergic synapse. Neuron 60:642-656.

Steinert JR, Robinson SW, Tong H, Haustein MD, Kopp-Scheinpflug C, Forsythe ID (2011) Nitric oxide is an activity-dependent regulator of target neuron intrinsic excitability. Neuron 71:291-305.

Taberner AM, Liberman MC (2005) Response properties of single auditory nerve fibers in the mouse. J Neurophysiol 93:557-569.

Turrigiano GG (1999) Homeostatic plasticity in neuronal networks: the more things change, the more they stay the same. Trends Neurosci 22: 221-227.

Turrigiano GG (2008) The self-tuning neuron: synaptic scaling of excitatory synapses. Cell 135:422-435.

van Staveren WC, Markerink-van Ittersum M, Steinbusch HW, Behrends S, de Vente J (2005) Localization and characterization of cGMP-immunoreactive structures in rat brain slices after NO-dependent and NOindependent stimulation of soluble guanylyl cyclase. Brain Res 1036:7789.

Vogler DP, Robertson D, Mulders WH (2011) Hyperactivity in the ventral cochlear nucleus after cochlear trauma. J Neurosci 31:6639_ 6645.

Wang X, Sachs MB (1992) Coding of envelope modulation in the auditory nerve and anteroventral cochlear nucleus. Philos Trans R Soc Lond B Biol Sci 336:399-402.

Wang X, Sachs MB (1994) Neural encoding of single-formant stimuli in the cat. II. responses of anteroventral cochlear nucleus units. J Neurophysiol 71:59-78

Wickesberg RE, Oertel D (1990) Delayed, frequency-specific inhibition in the cochlear nuclei of mice: a mechanism for monaural echo suppression. J Neurosci 10:1762-1768. 
Wigström H, Gustafsson B, Huang YY, Abraham WC (1986) Hippocampal long-term potentiation is induced by pairing single afferent volleys with intracellularly injected depolarizing current pulses. Acta Physiol Scand 126:317-319.

Wu SH, Oertel D (1984) Intracellular injection with horseradish peroxidase of physiologically characterized stellate and bushy cells in slices of mouse anteroventral cochlear nucleus. J Neurosci 4:1577-1588.

Wu SH, Oertel D (1987) Maturation of synapses and electrical properties of cells in the cochlear nuclei. Hear Res 30:99-110.

Zeng C, Yang Z, Shreve L, Bledsoe S, Shore S (2012) Somatosensory projections to cochlear nucleus are upregulated after unilateral deafness. J Neurosci 32:15791-15801.
Zhang S, Oertel D (1993) Tuberculoventral cells of the dorsal cochlear nucleus of mice: intracellular recordings in slices. J Neurophysiol 69: 1409-1421.

Zhou L, Zhu DY (2009) Neuronal nitric oxide synthase: structure, subcellular localization, regulation, and clinical implications. Nitric Oxide 20:223-230.

Zhuo M, Kandel ER, Hawkins RD (1994) Nitric oxide and cGMP can produce either synaptic depression or potentiation depending on the frequency of presynaptic stimulation in the hippocampus. Neuroreport 5:1033-1036.

Zucker RS, Regehr WG (2002) Short-term synaptic plasticity. Annu Rev Physiol 64:355-405. 